Running head: POWER, FOCUS, AND RESPONSIBILITY
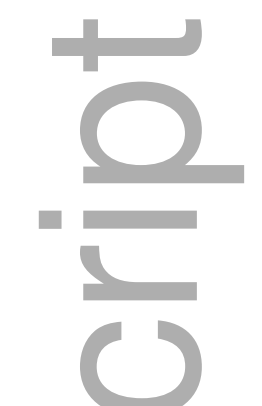

\title{
A matter of focus: Power-holders feel more responsible after adopting a cognitive other-focus, rather than a self-focus
}

Annika Scholl ${ }^{1}$, Kai Sassenberg ${ }^{1,2}$, Daan Scheepers ${ }^{3}$, Naomi Ellemers ${ }^{4}$, and Frank de Wit ${ }^{5}$

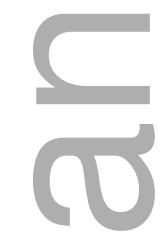

\footnotetext{
${ }^{1}$ Social Processes Lab, Leibniz-Institut für Wissensmedien, Germany

${ }^{2}$ University of Tübingen, Germany

${ }^{3}$ Leiden University, The Netherlands

${ }^{4}$ University of Utrecht, The Netherlands

${ }^{5}$ Melbourne Business School, Australia
}

This is the author manuscript accepted for publication and has undergone full peer review but has not been through the copyediting, typesetting, pagination and proofreading process, which may lead to differences between this version and the Version of Record. Please cite this article as doi:

$\underline{10.1111 / \text { bjso.12177 }}$

This article is protected by copyright. All rights reserved 
Word count (exc. figures/tables): 5161

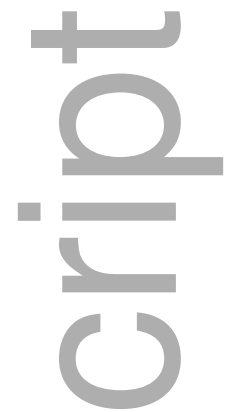

*Requests for reprints should be addressed to Annika Scholl, Social Processes Lab, IWM Tuebingen, Schleichstr.6, D-72076 Tuebingen, Germany (e-mail: a.scholl@iwm-tuebingen.de).

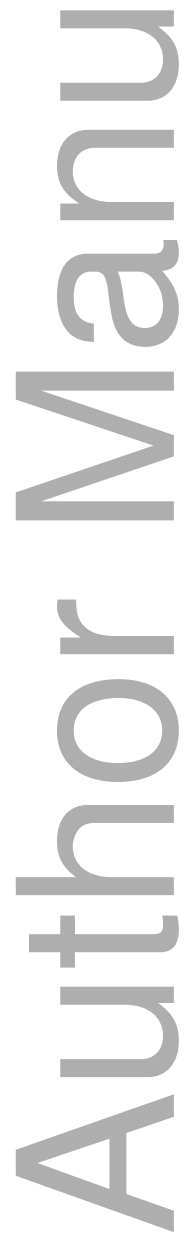




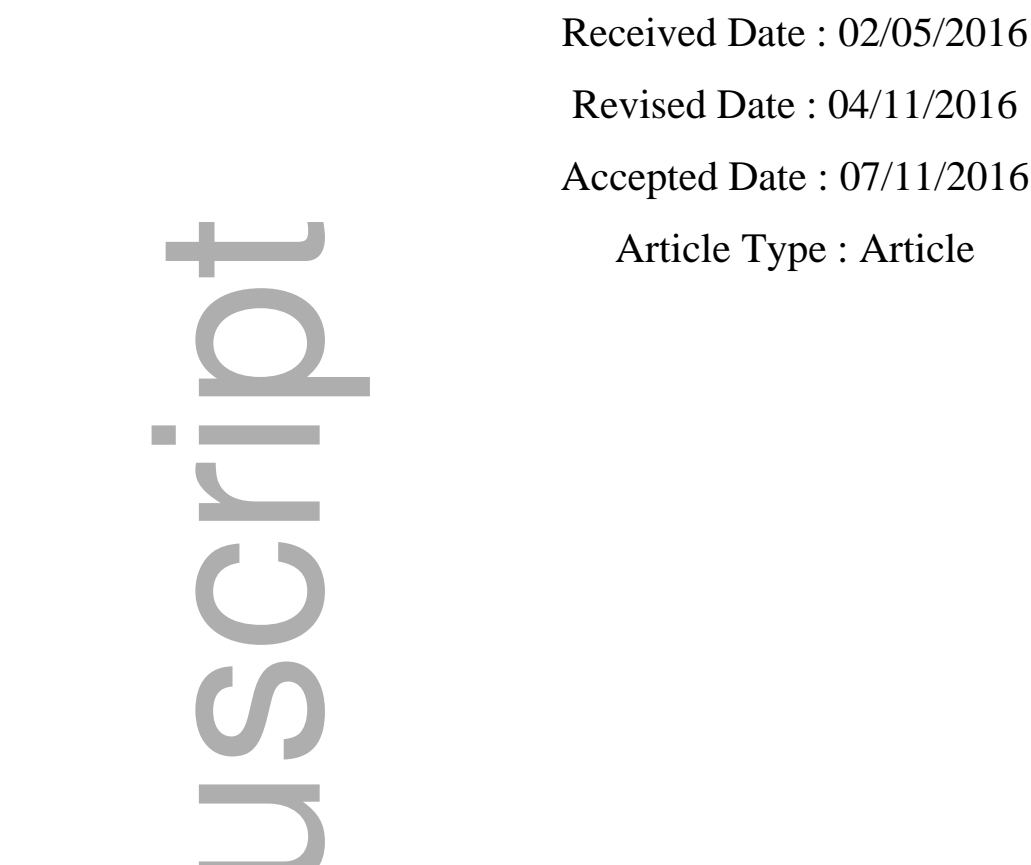

A matter of focus: Power-holders feel more responsible after adopting a cognitive otherfocus, rather than a self-focus

Word count: 5169 


\begin{abstract}
Social power implies responsibility. Yet, power-holders often follow only their own interests and overlook this responsibility. The present research illuminates how a previously adopted cognitive focus guides perceived responsibility when a person receives high (vs. low) power. In three experiments, adopting a cognitive focus on another person (vs. on the self or taking over another person's perspective) promoted perceived responsibility among individuals receiving high (but not low) power in a subsequent context. This effect was specific for perceived responsibility - a cognitive focus on another person did not change the perceived opportunity to pursue goals or the perceived relationship to an interaction partner (e.g., interpersonal closeness). While prior research examined how social values (i.e., chronically caring about others) guide responsibility among those holding power, the current findings highlight that mere cognitive processes (i.e., situationally focusing attention on others) alter perceived responsibility among those just about to receive power.
\end{abstract}

(147 words)

Keywords: Social power; construal of power; cognitive focus; responsibility; opportunity

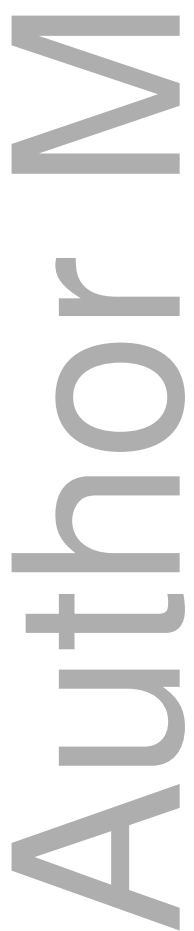


The opportunities to pursue goals resulting from elevated power are usually obvious. Yet, those holding power are not always aware of the responsibility their position affords. For instance, power-holders often prioritise their own over others' interests (see Lammers, Galinsky, Dubois, \& Rucker, 2016), objectify others (Gruenfeld, Inesi, Magee, \& Galinsky, 2008), show low concern about others' suffering (van Kleef et al., 2008), and at times even treat others aggressively (Fast \& Chen, 2009). However, there are also situations in which power-holders do recognise their responsibility, such as when they attend to others (Overbeck \& Park, 2001; Schmid Mast, Jonas, \& Hall, 2009), forgive an insult (Karremans \& Smith, 2010), or distribute work more fairly (Chen, Lee-Chai, \& Bargh, 2001), thereby fostering subordinates' motivation and organisational success (cf. De Hoogh \& Den Hartog, 2008).

But under which conditions do people perceive power to afford responsibility? The present research proposes that drawing the cognitive focus towards another person (rather than the self) will make individuals more aware of the responsibility a subsequent powerful position affords. We, thereby, seek to contribute to an understanding of the situational preconditions of construing (i.e., perceiving) a powerful position as responsibility.

\section{Social power construed as responsibility}

Social power means having asymmetric control over one's own and others' outcomes (Fiske \& Berdahl, 2007; Keltner, Gruenfeld, \& Anderson, 2003). This implies that the powerful can achieve goals relatively independently, whereas powerless people's situation rather depends on the power-holders' actions. Subjectively, individuals can be more or less aware of two aspects of their power - that is, they can construe a powerful position as providing opportunities and / or responsibilities. Construing high power as opportunity implies that power-holders experience freedom and feel enabled to do what they find important. Individuals are usually well aware of the opportunities (high) power affords; however, they often tend to overlook the responsibility (for a summary, see Sassenberg, Ellemers, Scheepers, \& Scholl, 2014).

Construing high power as responsibility means to experience an inner drive to take care of things that others cannot take care of. Due to others' dependence on the power-holder, construing power as responsibility signifies considering the others' situation. Accordingly, a power-holder may perceive more responsibility if the other person(s) — for instance, his/her subordinate-is somehow relevant to the power-holder. Indeed, individuals who are generally other-oriented, endorsing communal values, act more responsibly when given power (compared to a control condition; Chen et al., 2001; see also Côté et al., 2011; DeCelles, DeRue, Margolis, \& Ceranic, 2012; Gordon \& Chen, 2013). Similarly, individuals holding 
power treat another person more considerately when having a strongly committed relationship to the other (compared to a less committed relation; Karremans \& Smith, 2010), when being instructed to ensure others' wellbeing (vs. to boost overall performance; Overbeck \& Park, 2006), or putting themselves into the shoes of their powerless counterparts (vs. a control condition; Galinsky, Magee, Rus, Rothman, \& Todd, 2014). Similarly, individuals from Eastern cultures, which emphasize relations to others, are more likely to see power as responsibility (compared to Westerners, who tend to value individualistic concerns; Torelli \& Shavitt, 2011; Zhong et al., 2006).

Taken together, feelings (or behaviors) indicative of responsibility are raised among those holding power, if they personally value or care for other people. The current research aims to go beyond this in two ways. First, it seeks to show that the extent to which those in power perceive responsibility does not necessarily depend on their relationship to others and the value they attach to it (i.e., 'caring' for others, such as being generally concerned about others' well-being; e.g., Gordon \& Chen, 2013); rather, power-holders' perceived responsibility may also result from mere attention to and awareness of others - that is, a situationally activăted 'cognitive focus' on others (cf. Thompson, Cowan, \& Rosenhan, 1980). People can direct their attention to different aspects in a given situation, be it the self (e.g., "What is happening to me? How will my situation change?") or another person (e.g., "What is happening to others / them? How will their situation change?"). Focusing attention on other people, rather than the self, has been shown to influence a number of responses (e.g., it facilitates helping behavior towards another person; Thompson, Cowan, \& Rosenhan, 1980; or sympathy towards others, Harth, Kessler, \& Leach, 2008). Because such perceptual tendencies tend to carry-over from one situation to the next (e.g., Higgins \& Chaires, 1980; Landkammer \& Sassenberg, in press; Sassenberg, Moskowitz, Jacoby, \& Hansen, 2007), the focus on others (vs. on the self) might also alter the outcomes of gaining social power-here, perceived responsibility. Building upon this, we test whether adopting a cognitive focus on another person-who is unrelated to the power context — suffices to heighten the perceived responsibility that a subsequent powerful position provides.

Second, prior research so far outlined predictors of responsibility among people already holding power - that is, among people who have already developed a certain understanding of their power. The present research aims to go beyond this by examining people receiving a powerful role only later on, in an unrelated setting. It thereby investigates how a certain meaning of power, namely as affording responsibility, develops in the first place. 
We hypothesise that merely focusing attention on another person, rather than on the self, will promote power as responsibility in a subsequent context. In other words, an individual receiving high (compared to low) power should feel more responsible after having adopted a cognitive other- (versus a self-) focus. Note that this effect should be specific for high power. Low power positions provide little control over resources that affect oneself or others; hence, low-power individuals are likely to experience low responsibility, regardless of the cognitive focus they have adopted previously.

Notably, one may expect that responsibility is heightened not only when cognitively focusing on another person, but also when taking another person's perspective- that is, putting oneself into another person's shoes and imagining what oneself would think in this person's situation (Davis, 1983; Galinsky \& Moskowitz, 2000). Yet, in situations in which we have scarce knowledge about others' actual thoughts, perspective taking requires intuitions about others' perspectives - which usually heavily rely on one's own perspective. As such, perspective taking implies that (1) the own perspective (i.e., the self) is activated and projected on the other, but then (2) adjusted to the other person (so-called automatic egocentric anchoring and effortful adjustment; Epley \& Caruso, 2009; Epley \& Waytz, 2010; Nickerson, 1999). In short, when taking over another's perspective, the first that comes to mind is information about the self, serving as a starting point. Thus, perspective taking should render both the self and the other salient, whereas cognitively focusing on another person implies concentrating only on the other (i.e., without imagining the self in that same situation, or the relation between self and other; cf. Thompson et al., 1980). Accordingly, we expected that a cognitive other-focus, more so than a self-focus and potentially also perspective taking (because the latter also activates the self to some extent), promotes responsibility among those receiving high power.

\section{Overview of the present research}

Three experiments tested this hypothesis, inducing a cognitive other-/self-focus, then assigning low/high power-roles and measuring perceived responsibility in this power context. In doing so, we were able to test whether adopting an other-/self-focus alters how individuals construe subsequent power. Experiments 1 and 2 investigated assigned power-roles (Inesi, Botti, Rucker, \& Galinsky, 2011; Sassenberg et al., 2012), Experiment 3 used a subtle power manipulation (Weick \& Guinote, 2010).

Experiment 1 established how other-/self-focus impacts perceived responsibility when receiving high power. Experiments 2 and 3 then compared this effect for high versus low power to test whether cognitive focus, indeed, specifically affects individuals receiving high 
power. Moreover, Experiment 3 included an additional perspective taking condition. Though this was not our main focus in this research, we also sought to demonstrate that cognitive focus specifically alters perceived responsibility among those high vs. low in power, but not other outcomes - including perceived opportunity (Experiments 1-3) and, as indicators of the perceived relationship to one's powerful/powerless counterpart, interpersonal closeness to and objectification of the other (Experiment 2$){ }^{1}$

\section{Method}

\section{Experiment 1: Cognitive focus and high-power roles}

This experiment implemented two conditions (Focus: self- vs. other-focus). Seventysix undergraduates (55 female, 21 male; $M_{\text {age }}=23.37$ years; range: 18-39) participated in a package of three separate studies in exchange for $8 €$ (approximately $\$ 11$ ).

Participants completed a questionnaire of supposedly unrelated materials. They first recalled a past positive event that they personally (self-focus) or another person they knew or were acquainted with (other-focus) had experienced. Participants composed an essay on "What happened during this event?" and "What consequences did this event have for you [for the other person]?". To give some examples, participants recalled events such as finishing high school, passing a test, getting an internship, going abroad, or moving to another city, which had happened either to themselves or another person, respectively (e.g., an acquaintance; a family member; a distant or close friend; their partner). ${ }^{2}$

Afterwards, they indicated their current mood (six items; e.g., "content"; 1-not at all to 9-completely; $\alpha=.82$; unaffected by the focus manipulation, $\mathrm{t}<1$ ). Up to this point, the procedure was identical for Experiments 1-3.

Participants then received a high-power role in an unrelated sports scenario (adopted from Sassenberg et al., 2012), supposedly assessing their spontaneous opinion about some topics on sports events. They read that they were the organiser of a big sports event, who makes central decisions about measures (e.g., implementing mandatory drug tests, restricting video transmissions, investing money in new performance measurement techniques) to make the event a success. These measures impacted the athletes and their preparations (i.e., participants had high power by controlling their outcomes). Participants engaged in this role by making decisions whether or not they wanted to implement five such measures (indicating "yes" versus "no", respectively).

After making these decisions, we assessed their perceived responsibility within the sports scenario (5 items; "When making these decisions..." "...I feel partly responsible for others' situation”, “...I sometimes think about how my decisions impact others”, “...I need to 
take care of others' needs", “...I am concerned about others' wellbeing”, “...I consider how much I can expect from others"; $\alpha=.77$ ) and perceived opportunity while making their decisions as the sports event organiser (5 items; "I can see what the possibilities are", "I make use of possibilities to be successful", "I have more possibilities to reach my goals", "I can take the control", "I can follow my own ideas"; $\alpha=.78 ; 1-$ not at all to 9-completely; adapted from Scheepers, Ellemers, \& Sassenberg, 2013).

\section{Results and discussion}

A 2 (Focus: self- vs. other-focus) x 2 (Construal: perceived responsibility vs. perceived opportunity) mixed model analysis of variance with repeated measurement on the last factor construal showed a significant interaction, $\mathrm{F}(1,74)=6.46, \mathrm{p}=.013, \eta_{\mathrm{p}}{ }^{2}=.08$. As predicted, simple comparisons indicated that for perceived responsibility, an other-focus promoted responsibility $(\mathrm{M}=6.99, \mathrm{SD}=1.28)$, compared to a self-focus $(\mathrm{M}=6.36, \mathrm{SD}=$ $1.12), \mathrm{p}=.025, \mathrm{MD}($ mean difference $)=.63, \mathrm{CI}_{95 \%}=[.08 ; 1.18]$. No such effect was found for perceived opportunity $\left(\mathrm{M}_{\text {other-focus }}=6.29, \mathrm{SD}=1.19 ; \mathrm{M}_{\text {self-focus }}=6.63, \mathrm{SD}=1.06, \mathrm{p}=.197, \mathrm{MD}\right.$ $=.34, \mathrm{CI}_{95 \%}=[-.18 ; .85] .^{3}$

Providing first evidence for our predictions, adopting an other- (vs. self-) focus heightened the responsibility (but not opportunity) individuals perceived within their subsequent power-role. Experiment 2 sought to test whether this effect is, indeed, specific for high power. Furthermore, we aimed at demonstrating that cognitive focus specifically alters the perceived responsibility, but not, more generally, the interpersonal relationship to others in the subsequent power context (i.e., feeling closer to or objectifying others).

\section{Method}

\section{Experiment 2: Cognitive focus and high/low power}

This study implemented a 2 (Focus: self- vs. other-focus) x 2 (Power: low vs. high) design. Eighty-five undergraduates between the age of 18-30 years (50 females, 35 males; $\mathrm{M}_{\mathrm{age}}=21.92$ years) participated in exchange for a candy. ${ }^{4}$

We manipulated other-/self-focus and measured subsequent mood $(\alpha=.76$; unaffected by the manipulation, $\mathrm{F}<1$ ) as in Experiment 1 . We then induced high vs. low power following a procedure from Inesi et al. (2011). Participants imagined working with an interaction partner in a company. High power participants imagined being the manager of a team organising a company event with their assistants for their company. Low power participants enacted an assistant of a team organising such an event with their manager. They were then asked to complete a couple of 'regular work tasks', in fact comprising of some rolematching tasks to make their high versus low power position more realistic; this included 
checking their office on a floor plan after a move of the company, checking its interior decoration, and rating its adequateness (here, a spacious, single manager's office vs. a small, shared assistant's office; see Inesi et al., 2011).

With regard to the event to be organised, we then asked them about their 'expectations about the collaboration with their assistants / manager', in fact assessing objectification of their assistant / manager (10 items; e.g., "I think more about what this person can do for me than what I can do for him/her", $\alpha=.69 ; 1$-completely disagree to 7-completely agree; Gruenfeld et al., 2008), interpersonal closeness to the other (one item; IOS scale; Aron, Aron, Tudor, \& Nelson, 1991), and the perceived responsibility $(\alpha=.64)$ and opportunity of the manager $(\alpha=.66$, with the same items as in Experiment 1). As power manipulation check, seven items assessed how powerful/powerless participants felt within their role (e.g., submissive-dominant; 9-point scales; $\alpha=.81$; Smith, Wigboldus, \& Dijksterhuis, 2008).

\section{Results and discussion}

A 2 (Focus) x 2 (Power) analysis of variance (ANOVA) yielded a main effect of Power on the power manipulation check, $\mathrm{F}(1,81)=17.65, \mathrm{p}<.001, \eta_{\mathrm{p}}{ }^{2}=.18\left(\mathrm{M}_{\text {high-power }}=\right.$ $\left.6.57, \mathrm{SD}=.99 ; \mathrm{M}_{\text {low-power }}=5.59, \mathrm{SD}=1.12\right)$ and no Focus main effect or interaction $(\mathrm{Fs}<2$, ps > .17). Hence, subjectively experienced power was unaffected by the focus manipulation and the power manipulation was successful.

We expected that individuals receiving high (compared to low) power would perceive more responsibility after adopting an other-focus, but not a self-focus. An ANOVA yielded no main effect of Focus $(F<1)$, but a main effect of Power, $F(1,81)=18.23, p<.001, \eta_{p}{ }^{2}=$ .18 , qualified by the predicted Focus $x$ Power interaction, $F(1,81)=4.39, p=.039, \eta_{p}^{2}=.05$ (see Figure 1 and Table 1). As expected, simple comparisons demonstrated that after adopting an other-focus, high-power participants felt more responsible $(\mathrm{M}=6.57, \mathrm{SD}=.84)$ than lowpower participants $(\mathrm{M}=5.13, \mathrm{SD}=.97), \mathrm{F}(1,81)=20.98, \mathrm{p}<.001, \eta_{\mathrm{p}}^{2}=.21, \mathrm{MD}=1.44$, $\mathrm{CI}_{95 \%}=[.82 ; 2.07]$; this was not the case after adopting a self-focus $\left(\mathrm{M}_{\text {high power }}=5.95, \mathrm{SD}=\right.$ $\left.1.26 ; \mathrm{M}_{\text {low power }}=5.46, \mathrm{SD}=1.06\right), \mathrm{F}(1,81)=2.29, \mathrm{p}=.134, \eta_{\mathrm{p}}{ }^{2}=.03, \mathrm{MD}=.49, \mathrm{CI}_{95 \%}=[-$ .16.; 1.14]. Put differently, focus did not influence perceived responsibility among low-power $(\mathrm{p}=.304)$, but rather among high-power participants $(\mathrm{p}=.058)$.

An analogous analysis for perceived opportunity yielded a marginal effect of Focus, $\mathrm{F}(1,81)=3.07, \mathrm{p}=.084, \eta_{\mathrm{p}}{ }^{2}=.04\left(\mathrm{M}_{\text {other-focus }}=6.30, \mathrm{SD}=1.12 ; \mathrm{M}_{\text {self-focus }}=6.69, \mathrm{SD}=.90\right)$, but no other significant effects ( Fs $<2$, ps $<.20)$. Moreover, objectification of the interaction partner was unaffected by Power, Focus, and the interaction $\left(\mathrm{M}_{\mathrm{other} \text {-focus } / \text { low-power }}=4.33, \mathrm{SD}=\right.$ $.80 ; \mathrm{M}_{\text {other-focus } / \text { high-power }}=4.30, \mathrm{SD}=.89 ; \mathrm{M}_{\text {self-focus }} /$ low-power $=4.27, \mathrm{SD}=.66 ; \mathrm{M}_{\text {self-focus }} /$ high- 
power $=4.19, \mathrm{SD}=.99 ; \mathrm{Fs}<1, \mathrm{ps}<.625)$. Similarly, interpersonal closeness to the interaction partner was affected by Power, $\mathrm{F}(1,81)=4.90, \mathrm{p}=.030, \eta_{\mathrm{p}}{ }^{2}=.06$, but not by Focus or an interaction between the two $\left(\mathrm{M}_{\text {other-focus } / \text { low-power }}=3.22, \mathrm{SD}=1.04 ; \mathrm{M}_{\text {other-focus } / \text { high-power }}=3.86\right.$, $\mathrm{SD}=1.24 ; \mathrm{M}_{\text {self-focus }} /$ low-power $=3.40, \mathrm{SD}=.94 ; \mathrm{M}_{\text {self-focus }} /$ high-power $=3.81, \mathrm{SD}=1.12 ; \mathrm{Fs}<1$, ps $>.628)$.

In sum, after adopting an other-focus (but not a self-focus), people receiving high power did, indeed, feel more responsible than those receiving low power. Put differently, cognitive focus specifically seemed to affect those receiving high power (but not those with low power). Importantly, cognitive focus specifically changed how (high vs. low) power affects felt responsibility, but not perceived opportunities to pursue goals. Moreover, we found effects of power $x$ focus neither on objectification nor interpersonal closeness to their subsequent interaction partner; this suggests that even though power-holders became more aware of their responsibility than those low in power after adopting an other-focus, this did not seem to change the, overall, perceived relationship to their counterpart. Because we assessed objectification and interpersonal closeness rather directly, however, future research might seek to replicate this with less explicit measurements.

Note that Experiments 1 and 2 used well-established, but rather explicit power roles. To rule out potential demand effects, Experiment 3 implemented subtler power differences (Fiske \& Dépret, 1996; Weick \& Guinote, 2010). Furthermore, we tested our more specific hypothesis that power-holders feel more responsible (than the powerless) when focusing on another person (i.e., attending to what is happening to another person), similar to or potentially more so than when taking the other's perspective (i.e., imagining oneself in the other person's situation).

\section{Experiment 3: Cognitive focus, perspective taking, and a high- vs. low-power role}

\section{Method}

We implemented a 3 (Focus: self- vs. other-focus vs. perspective taking) x 2 (Power: low vs. high) design. Eighty-nine undergraduates (72 female, 17 male; $\mathrm{M}_{\mathrm{age}}=23.34$ years; range: 18-50) participated in an online study for the chance of winning 10€-Amazonvouchers. ${ }^{5}$ Identical to Experiments 1 and 2, we manipulated cognitive focus and assessed subsequent mood $(\alpha=.79$; unaffected by the manipulation, $\mathrm{F}<1$ ).

In the additional perspective taking condition, participants recalled another person's positive event from this person's perspective and composed an essay recounting what had happened and the consequences of the event, as if they were in this person's situation 
(Galinsky \& Moskowitz, 2000; Skorinko \& Sinclair, 2013; italics highlight central differences to the other-focus manipulation).

For the subsequent power manipulation (adapted from Weick \& Guinote, 2010), participants saw five products (e.g., a radio, inline skates) with names, ostensibly created by 'another participant' for a contest. Our participants' task was to evaluate the innovativeness of each product name. High-power participants learned their evaluation would be entered into an equation and contribute to $50 \%$ of the final evaluation determining the winner (i.e., participants influenced the "other participant's" outcome). Low-power participants read their evaluation was of interest, but would not determine the winner (i.e., participants did not influence the "other participant's" outcome). Their own perceived responsibility and opportunity during this evaluation task were assessed with the same items as before $(\alpha=.70$ and .64, respectively). Finally, we measured interpersonal closeness, as an indicator of the perceived relationship to 'the other participant', as in Experiment 2 (one item; Aron et al., 1991).

\section{Results and discussion}

Following procedures from Experiment 2, we tested whether those receiving high (compared to low) power felt more responsible after adopting an other-focus, but not a selffocus or potentially taking over the other's perspective. A 3 (Focus: other- vs. self-focus vs. perspective taking) x 2 (Power: high vs. low) ANOVA for perceived responsibility showed no main effect of Focus $(F<1, p=.705)$, but a main effect of Power, $F(1,83)=6.59, p=.012$, $\eta_{\mathrm{p}}{ }^{2}=.07$, qualified by the predicted Focus x Power interaction, $\mathrm{F}(2,83)=3.32, \mathrm{p}=.041, \eta_{\mathrm{p}}{ }^{2}=$ .07 (see Figure 2 and Table 1). Supporting our predictions, simple between-cell comparisons showed that after adopting an other-focus, high-power participants perceived more responsibility $(\mathrm{M}=5.42, \mathrm{SD}=2.03)$ than low-power participants $(\mathrm{M}=3.13, \mathrm{SD}=1.69), \mathrm{F}(1$, $83)=12.62, \mathrm{p}=.001, \eta_{\mathrm{p}}{ }^{2}=.13, \mathrm{MD}=2.28, \mathrm{CI}_{95 \%}=[1.01 ; 3.56]$. In contrast, high- and lowpower participants' perceived responsibility did not differ after adopting a self-focus $\left(\mathrm{M}_{\mathrm{high}}\right.$ power $\left.=4.01, \mathrm{SD}=1.85 ; \mathrm{M}_{\text {low power }}=3.86, \mathrm{SD}=1.43\right), \mathrm{F}<1, \mathrm{p}=.795, \mathrm{MD}=.15, \mathrm{CI}_{95 \%}=[-$ $1.02 ; 1.33]$ or after taking over the other's perspective $\left(\mathrm{M}_{\text {high power }}=4.18, \mathrm{SD}=1.55 ; \mathrm{M}_{\text {low power }}\right.$ $=3.74, \mathrm{SD}=1.88), \mathrm{F}<1, \mathrm{p}=.532, \mathrm{MD}=.44, \mathrm{CI}_{95 \%}=[-.96 ; 1.85]$. Put differently, simple comparisons for high power participants showed that, compared to a self-focus, an otherfocus promoted responsibility $(\mathrm{p}=.039$ ), whereas perspective taking did not do so to the same extent ( $\mathrm{p}=.806$; perspective taking vs. other-focus: $\mathrm{p}=.090$ ); in contrast, cognitive focus did not change low power participants' responsibility (ps > .197). 
Analyses for perceived opportunity revealed no significant effects (Fs $<1$, ps $>.434$ ), replicating Experiments 1 and 2. Once again, there was neither an effect of Focus $(\mathrm{F}<1)$, nor a Focus $x$ Power interaction $(F<1$, see Experiment 2$)$, nor a Power main effect, $F(1,83)=$ $2.20, \mathrm{p}=.142, \eta_{\mathrm{p}}{ }^{2}=.03$ on interpersonal closeness (indicating that the unpredicted main effect from Experiment 2 did not replicate here). This suggests that, as in Experiment 2, Focus did not alter the perceived relationship to 'the other participant' when given high vs. low power.

Taken together, these findings supported our predictions with a subtler power induction, ruling out potential demand effects. When being other-focused (i.e., simply focusing attention on another person), power-holders felt more responsible than the powerless; this was not the case when focusing on the self and, seemingly, also much less when taking over another person's perspective (i.e., putting oneself in the other's shoes).

\section{Meta-analysis of findings across Experiments 1-3}

Note that both Experiments 2 and 3 tested the effect of low versus high power on perceived responsibility in the other- versus self-focus condition. We performed a metaanalysis on the results for these effects across Experiments 2 and 3 to test the robustness of our effect on perceived responsibility. To this end, we calculated the mean effect size $r$, weighed for sample size, for the most critical comparison - here, the effect of high versus low power in the other-focus and in the self-focus condition. A meta-analysis across these two studies found a medium effect of power on perceived responsibility in the other-focus condition, $\mathrm{r}=.282,95 \% \mathrm{CI}=[.133 ; .419]$, but not in the self-focus condition, $\mathrm{r}=.097,95 \%$ $\mathrm{CI}=[-.059 ; .248]$.

Moreover, Experiments 1-3 all implemented a self-focus / high-power and an otherfocus / high-power condition (and different additional conditions across experiments). A similar meta-analysis for the effect of self-focus / high-power versus other-focus / high-power on perceived responsibility revealed a (small to medium) significant effect across the data of all three studies, $\mathrm{r}=.242, \mathrm{p}=.002,95 \% \mathrm{CI}=[.079 ; .393]$. The interval of effect sizes here was very small, . $224<\mathrm{r}<.258$, indicating that effect sizes for Experiments 1, 2 and 3 were highly similar. Across our studies, this provides additional support for the differential effect of adopting focus on another person (rather than on the self) on perceived responsibility among those that receive high (compared to low) power.

\section{General Discussion}

Power affords responsibility to take care of things others cannot take care of (e.g., important decisions or others' interests), though those in power often seem to overlook this responsibility. Three experiments demonstrated that individuals receiving high power feel 
more responsible (than those low in power) after adopting a cognitive focus on another person (rather than when focusing on the self). In all studies, other-/self-focus was completely unrelated to the power context, ruling out potential demand effects.

Cognitive focus affected power-holders' experienced responsibility (Experiment 1-3), but did not alter the perceived relationship with a subsequent interaction partner, in terms of the partner's perceived usefulness (i.e., objectification) or one's interpersonal closeness to the partner (Experiments 2 and 3). Notably, our focus manipulation instructed the recall of positive events, in order to prevent inducing affective reactions like empathy and compassion with (others') negative experiences (rather than a mere cognitive focus on others). While the recall of (others') positive events may induce some envy towards others' successes, our checks on participants' current mood (unaffected by self-/other-focus) indicate that this was unlikely the case; yet, future research may implement a different focus manipulation to replicate the effects without an explicit focus on positive events. As potential limitation, our studies used rather small samples (see Footnote 1); future research should, thus, seek to replicate the effects with larger sample sizes to promote the generalizability of findings.

Our findings relate to prior research indicating that power-holders are often less responsive to others, for instance, show less motor resonance on the neurological level when observing others' actions (Hogeveen, Inzlicht, \& Obhi, 2013) or less compassion when others tell them about their negative experiences (van Kleef et al., 2006). For instance, in van Kleef et al.'s (2006) study, participants first recalled a personal negative experience (similar to our self-focus condition, except for the negative valence of the event), after which their compassion for their interaction partner was assessed in direct dyadic interactions. Results here indicated that the higher participants' general sense of power was, the less compassion they exhibited towards their partner-suggesting that, similar to our self-focus condition, after recalling a personal experience, power-holders may not have recognised their responsibility. Similarly, participants recalling a personal high vs. low power event (vs. control) subsequently showed less motor resonance to others' actions (Hogeveen et al., 2013). Extending these results, our findings suggest that when not a self-focus, but rather a focus on another person is induced, power-holders' are likely to better recognise their responsibility.

Furthermore, our findings go beyond previous research in several ways. First, prior observations showed that responsibility-related tendencies arise when power-holders generally value others' wellbeing (in terms of their cultural background; Torelli \& Shavitt, 2010, 2011; Zhong et al., 2006) or care for others (e.g., in terms of traits; Chen et al., 2001; Côté et al., 2011; DeCelles et al., 2012; in terms of independent versus interdependent self- 
construal; Gordon \& Chen, 2013; or in terms of relationship commitment, Karremans \& Smith, 2010). Our results indicate that perceived responsibility in power contexts does not necessarily depend on the specific relationship to another person; instead, these effects of cognitively focusing on another person - that is, attending to what happens to another person - can likely carry-over from one situation to another, similar to a mindset that can be activated in one context and carries over to subsequent situations (e.g., Higgins \& Chaires, 1980; Sassenberg, Moskowitz, Jacoby, \& Hansen, 2007).

Second, the current studies directly assess construal of power as responsibility, whereas most previous research focused on (behavioral) results of such a construal of power (e.g., Sassenberg at al., 2012; De Wit et al. 2016). Combining these two approaches, such as investigating both the construal of power as responsibility and its subsequent behavioral implications, would be a fruitful next step. Finally, previous studies indicate how situational factors (e.g., perspective taking; goals; Galinsky et al., 2014; Overbeck \& Park, 2006) promote individualization and fairness towards others among individuals yielding power (i.e., who have already developed a specific understanding of their power). These findings support the idea that, once having power, situationally activated tendencies (e.g., goals) do especially guide those high in power, more so than those low in power (see Guinote, 2007; Guinote, Weick, \& Cai, 2012). Beyond these approaches, the present research looked at a predictor of the development of a certain understanding of power, before people possess power in the first place (cf. Sassenberg et al., 2012). Combined with the previous findings, this suggests that situational tendencies (here, a cognitive focus) that are activated before having power may, likewise, guide how people perceive (and potentially enact) power, outlining fruitful avenues for future research. Beyond this, additional exploration of our findings speaks to the idea that those high (versus low) in power react more flexibly, depending on the specific situation (cf. Guinote, 2007) — here, depending on their previously adopted cognitive focus.

Note that except in Experiment 3, we consistently compared other-/self-focus. Hence, the data does not allow for conclusions whether other-focus increases or self-focus diminishes the effects of high vs. low power. Theoretically, both could be the case. Yet, prior research suggests that usually the self is salient (e.g., Epley \& Caruso, 2009; Flavell, 1977; Nickerson, 1999), especially among power-holders (who show more ego-centrism; see Lammers et al., 2016). This suggests that our effects might be more likely driven by inducing an other-focus (rather than self-focus); our data from Experiments 2 and 3 also seem to suggest so, indicating that the high power-other-focus condition is the one most clearly differing from all other conditions. Moreover, Experiment 2 included a perspective taking condition which likely has 
activated both the salience of self and other-because putting oneself into another person's shoes implies using the own 'egocentric' perspective as a starting point and then adjusting it to the other person (cf. Epley \& Caruso, 2009; Epley \& Waytz, 2010; Nickerson, 1999). Perspective taking yielded results more similar to a self-focus than other-focus. Together, this suggests that the effects may be more likely driven by other-focus than by self-focus. Nonetheless, future research might establish this more explicitly with a neutral control condition (e.g., lowering the focus on both the self and the other) and test under which conditions perspective taking may become more beneficial (e.g., when taking the perspective of the very person one has power over; see Galinsky et al., 2014).

In terms of practical implications, the findings are relevant to situations in which power-holders act on behalf of others without clearly focusing on (these) others. For instance, many power-holders make important decisions in committees, management meetings, or advisory boards with other power-holders, but without their powerless counterparts who will be impacted by these decisions. According to the present findings, designing such situations in a way that promotes a focus on and an awareness of others (rather than the self) may contribute to power-holders' responsibility (i.e., their concern for others' outcomes), which outlines potential ways for practical interventions to be tested.

To conclude, the present research helps to understand how individuals may be made aware of the responsibility that a powerful role entails. While prior research examined individual differences or rather stable aspects of the task or context, the present work highlights a situational predictor, on the cognitive level, that can be altered before individuals gain power in the first place. Drawing attention to another person transfers from one situation to the next, and it helps individuals to recognise the responsibility implied in a high-power role. This provides a promising starting point for interventions that draw individuals' awareness to others, rather than the self, when they will receive a powerful position.

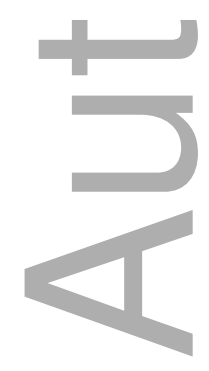




\section{References}

Aron, A. U., Aron, E. N., \& Smollan, D. (1992). Inclusion of other in the self scale and the structure of interpersonal closeness. Journal of Personality and Social Psychology, 63, 596-612. doi:10.1037/0022-3514.63.4.596

Chen, S., Lee-Chai, A. Y., \& Bargh, J. A. (2001). Relationship orientation as a moderator of the effects of social power. Journal of Personality and Social Psychology, 80, 173187. doi: $10.1037 / 0022-3514.80 .2 .173$

Côté, S., Kraus, M. W., Cheng, B. H., Oveis, C., van der Löwe, I., Lian, H., \& Keltner, D. (2011). Social power facilitates the effect of prosocial orientation on empathic accuracy. Journal of Personality and Social Psychology, 101, 217-232. doi:10.1037/a0023171

Davis, M. H. (1983). Measuring individual differences in empathy: Evidence for a multidimensional approach. Journal of Personality and Social Psychology, 44, 113126. doi:10.1037/0022-3514.44.1.113

De Hoogh, A. H. B., \& Den Hartog, D. N. (2008). Ethical and despotic leadership, relationships with leader's social responsibility, top management team effectiveness and subordinates' optimism: A multi-method study. Leadership Quarterly, 19, 297311. doi: 10.1016/j.leaqua.2008.03.002

DeCelles, K. A., DeRue, D. S., Margolis, J. D., \& Ceranic, T. L. (2012). Does power corrupt or enable? When and why power facilitates self-interested behavior. Journal of Applied Psychology, 97, 681-689. doi:10.1037/a0026811

DeWit, F., Scheepers, D., Ellemers, N., Sassenberg, K., \& Scholl, A. (2016). When do those in power take advice? The role of power as opportunity vs. responsibility. Unpublished manuscript.

Epley, N., \& Caruso, E. M. (2009). Perspective taking: Misstepping into others' shoes. In K. D. Markman, W. M. P. Klein, \& J. A. Suhr (Eds.), Handbook of imagination and mental simulation (pp. 295-309). New York, NY: Psychology Press.

Epley, N., \& Waytz, A. (2010). Mind perception. In S. T. Fiske, D. T. Gilbert, \& G. Lindzey (Eds.), Handbook of social psychology (Vol. 1, 5th ed., pp. 498-541). Hoboken, NJ: John Wiley.

Fast, N. J., \& Chen, S. (2009). When the boss feels inadequate: Power, incompetence, and aggression. Psychological Science, 20, 1406-1413. doi: 10.1111/j.14679280.2009.02452.x

Fiske, S. T., \& Berdahl, J. (2007). Social power. In A. W. Kruglanski \& E. T. Higgins (Eds.), 
Social psychology: Handbook of basic principles (2nd ed.). (pp. 678-692). New York, NY US: Guilford Press.

Fiske, S. T., \& Dépret, E. (1996). Control interdependence and power: Understanding social cognition in its social context. In W. Stroebe \& M. Hewstone (Eds.), European review of social psychology (Vol. 7, pp. $31-61$ ). New York: Wiley.

Flavell, J. H. (1977). Cognitive development. Englewood Cliffs, NJ: Prentice Hall.

Galinsky, A. D., \& Moskowitz, G. B. (2000). Perspective-taking: Decreasing stereotype expression, stereotype accessibility, and in-group favoritism. Journal of Personality and Social Psychology, 78, 708-724. doi:10.1037/0022-3514.78.4.708

Galinsky, A. D., Magee, J. C., Rus, D., Rothman, N. B., \& Todd, A. R. (2014). Acceleration with steering: The synergistic benefits of combining power and perspective-taking. Social Psychological and Personality Science, 5, 627-635.

Gordon, A. M., \& Chen, S. (2013). Does power help or hurt? The moderating role of selfother focus on power and perspective-taking in romantic relationships. Personality And Social Psychology Bulletin, 39, 1097-1110. doi: 10.1177/0146167213490031

Gruenfeld, D. H., Inesi, M. E., Magee, J. C., \& Galinsky, A. D. (2008). Power and the objectification of social targets. Journal of Personality and Social Psychology, 95, 111-127. doi: 10.1037/0022-3514.95.1.111

Guinote, A. (2007). Behavior variability and the Situated Focus Theory of Power. European Review of Social Psychology, 18, 256-295. doi: 10.1080/10463280701692813

Guinote, A., Weick, M., \& Cai, A. (2012). Does power magnify the expression of dispositions? Psychological Science. doi: 10.1177/0956797611428472

Harth, N. S., Kessler, T., \& Leach, C. W. (2008). Advantaged Group's Emotional Reactions to Intergroup Inequality: The Dynamics of Pride, Guilt, and Sympathy. Personality \& Social Psychology Bulletin, 34(1), 115-129. doi:10.1177/0146167207309193

Higgins, E. T., \& Chaires, W. M. (1980). Accessibility of interrelational constructs: Implications for stimulus encoding and creativity. Journal of Experimental Social Psychology, 16(4), 348-361. doi: 10.1016/0022-1031(80)90027-X

Inesi, M. E., Botti, S., D., D., Rucker, D. D., \& Galinsky, A. (2011). Power and choice: Their dynamic interplay in quenching the thirst for personal control. Psychological Science, 22, 1042-1048. doi: 10.1177/0956797611413936

Karremans, J. C., \& Smith, P. K. (2010). Having the power to forgive: When the experience of power increases interpersonal forgiveness. Personality and Social Psychology Bulletin, 36, 1010-1023. doi: 10.1177/0146167210376761 
Landkammer, F., \& Sassenberg, K. (in press). Competing while cooperating with the same others: The consequences of conflicting demands in co-opetition. Journal of Experimental Psychology: General.

Nickerson, R. S. (1999). How we know—and sometimes misjudge — what others know: Imputing one's own knowledge to others. Psychological Bulletin, 125, 737-759. doi:10.1037/0033-2909.125.6.737

Overbeck, J. R., \& Park, B. (2001). When power does not corrupt: Superior individuation processes among powerful perceivers. Journal of Personality and Social Psychology, 81, 549-565. doi: 10.1037/0022-3514.81.4.549

Overbeck, J.R., \& Park, B. (2006). Powerful perceivers, powerless objects: Flexibility of powerholders' social attention. Organizational Behavior and Human Decision Processes, 99, 227-243. doi:10.1016/j.obhdp.2005.10.003

Keltner, D., Gruenfeld, D. H., \& Anderson, C. (2003). Power, approach, and inhibition. Psychological Review, 110, 265-284. doi: 10.1037/0033-295X.110.2.265

Sassenberg, K., Moskowitz, G.B., Jacoby, J., \& Hansen, N. (2007). The carry-over effect of competition: The impact of competition on prejudice towards uninvolved outgroups. Journal of Experimental Social Psychology, 43, 529-538. doi:

10.1016/j.jesp.2006.05.009

Sassenberg, K., Ellemers, N., \& Scheepers, D. (2012). The attraction of social power: The influence of construing power as opportunity versus responsibility. Journal of Experimental Social Psychology, 48, 550-555. doi: 10.1016/j.jesp.2011.11.008

Sassenberg, K., Ellemers, N., Scheepers, D., \& Scholl, A. (2014). "Power corrupts" revisited: The role of construal of power as opportunity or responsibility. In J.-W. van Prooijen \& P. A. M. van Lange (Eds.), Power, politics, and paranoia: Why people are suspicious about their leaders. Cambridge, UK: Cambridge University Press.

Scheepers, D., Ellemers, N., \& Sassenberg, K. (2013). Power in group contexts: The influence of group status on promotion and prevention decision making. British Journal of Social Psychology, 52, 238-254. doi:10.1111/j.2044-8309.2011.02063.x

Scholl, A., \& Sassenberg, K. (2014). Where could we stand if I had...? How social power impacts counterfactual thinking after failure. Journal of Experimental Social Psychology, 53, 51-61. doi: 10.1016/j.jesp.2014.02.005

See, K. E., Morrison, E. W., Rothman, N. B., \& Soll, J. B. (2011). The detrimental effects of power on confidence, advice taking, and accuracy. Organizational Behavior and Human Decision Processes, 116, 272-285. doi: 10.1016/j.obhdp.2011.07.006 
Skorinko, J. L., \& Sinclair, S. A. (2013). Perspective taking can increase stereotyping: The role of apparent stereotype confirmation. Journal of Experimental Social Psychology, 49, 10-18. doi:10.1016/j.jesp.2012.07.009

Smith, P., Wigboldus, D., \& Dijksterhuis, A. (2008). Abstract thinking increases one's sense of power. Journal of Experimental Social Psychology, 44, 378-385. doi:

10.1016/j.jesp.2006.12.005

Thompson, W. C., Cowan, C. L., \& Rosenhan, D. L. (1980). Focus of attention mediates the impact of negative affect on altruism. Journal of Personality and Social Psychology, 38, 291-300. doi:10.1037/0022-3514.38.2.291

Torelli, C. J., \& Shavitt, S. (2010). Culture and concepts of power. Journal of Personality and Social Psychology, 99, 703-723. doi: 37/a0019973

Torelli, C. J., \& Shavitt, S. (2011). The impact of power on information processing depends on cultural orientation. Journal of Experimental Social Psychology, 47, 959-967. doi: 10.1016/j.jesp.2011.04.003

Tost, L. P., Gino, F., \& Larrick, R. P. (2012). Power, competitiveness, and advice taking: Why the powerful don't listen. Organizational Behavior and Human Decision Processes, 117, 53-65. doi: 10.1016/j.obhdp.2011.10.001

van Kleef, G. A., Oveis, C., van der Löwe, I., LuoKogan, A., Goetz, J., \& Keltner, D. (2008). Power, Distress, and Compassion: Turning a Blind Eye to the Suffering of Others. Psychological Science, 19, 1315-1322. doi:10.1111/j.1467-9280.2008.02241.x

Weick, M., \& Guinote, A. (2010). How long will it take? Power biases time predictions. Journal of Experimental Social Psychology, 46, 595-604. doi: 10.1016/j.jesp.2010.03.005

Zhong, C., Magee, J. C., Maddux, W. W., \& Galinsky, A. D. (2006). Power, culture, and action: Considerations in the expression and enactment of power in East Asian and Western societies. In M. A. N. E.A. Mannix, \& Y. Chen (Ed.), Research on managing in teams and groups (Vol. 9, pp. 53-73). Greenwich CT: Elsevier Science Press. 


\section{Footnotes}

${ }^{1}$ For all studies, we pre-determined ideal minimum sample size $(\mathrm{N}=25$ per condition as a standard procedure at that time; this could not be reached for Experiment 3 as, most likely due to the time of data collection during the semester break, not more participants could be recruited for this online study), the start/end point of data collection, and report all conditions and main measures targeting the present research question. Some studies assessed additional exploratory measures, which are available upon request.

${ }^{2}$ Note that our instructions did not imply that the other person was personally close to participants; still, some participants here recalled events of a rather close than more distant other person. Findings from Karremans and Smith (2010) suggest that closeness to others moderates the effects among those already holding power (in their studies, on interpersonal forgiveness); accordingly, we tested if our effects of other-focus differ, depending on the closeness to the other, by coding closeness (1=distant other, like acquaintance or friend, $2=$ close other, like good friend or partner). Across studies, the effects of other-focus on (highand low-power) participants' perceived responsibility did not differ for those recalling a close vs. distant other's event. Hence, cognitive focus on another person (independent how close to the participants) seemed to produce the effects. We thus do not discuss these differences in more detail here.

${ }^{3}$ We also explored whether other-focus promotes responsibility independent of who is present in the subsequent power context, or only when power-holders face a subsequent powerless (i.e., subordinate) rather than a powerful target (e.g., a fellow leader). Experiment 1 thus included Target (lower-power-target vs. same-power-target) as an additional factor. Participants learned their decisions would either impact the athletes ' preparations (lowerpower-target; $\mathrm{N}=76$ ), as described above, or would be made with committee-members (samepower-target; an additional $\mathrm{N}=77$ ). A 2 (Focus: self vs. other) x 2 (Target: lower- vs. samepower-target) ANOVA for perceived responsibility yielded a main effect of Focus, $\mathrm{F}(1,149)=$ $4.65, \mathrm{p}=.033, \eta_{\mathrm{p}}^{2}=.03$. Other-focus promoted responsibility $(\mathrm{M}=6.93, \mathrm{SD}=1.33)$, compared to self-focus $(\mathrm{M}=6.48, \mathrm{SD}=1.19)$, regardless of Target. There was neither a main effect of Target nor a Focus x Target interaction (Fs $<1$ ). Though the interaction was far from significant, Focus did not alter responsibility when the target person was also high in power $\left(\mathrm{M}_{\text {self-focus/same-power-target }}=6.61, \mathrm{SD}=1.26 ; \mathrm{M}_{\text {other-focus/same-power-target }}=6.86, \mathrm{SD}=1.39 ; \mathrm{p}=.383\right)$, but it did so when the target was lower in power $\left(\mathrm{M}_{\text {self-focus/lower-power-target }}=6.36, \mathrm{SD}=1.12\right.$; $\mathrm{M}_{\text {other-focus/lower-power-target }}=7.00, \mathrm{SD}=1.28 ; \mathrm{p}=.032$ ). There were no effects on perceived opportunity (Fs $<1.27$, ps $>.261)$. As the current research was interested in responsibility 
towards low-power others, the data reported for Experiment 1, and the following two experiments, focus only on low-power others.

${ }^{4}$ Two additional participants (one from the low-power/self-focus and highpower/other-focus condition each) failing to fulfill the basic study requirement of being an undergraduate $<30$ years, for whom this study was explicitly designed, were excluded; including these two cases yields similar, slightly weaker results. This study included an additional exploratory, supposedly neutral, condition; here, participants were asked to describe a healthy diet (i.e., what a healthy diet means, what its consequences are; perceived responsibility: $\left.\mathrm{M}_{\text {low power }}=5.11, \mathrm{SD}=1.60 ; \mathrm{M}_{\text {high power }}=6.29, \mathrm{SD}=1.17\right)$; simple between-cell comparisons yielded no significant differences of this condition to the self- or other-focus conditions for high or low power, all ps > .337. On the descriptive level, low power participants in this condition seemed to perceive a similar amount of responsibility as in the other-focus condition, rather than the self-focus condition; for high power, perceived responsibility in this condition lay somewhat in between the self-focus and other-focus condition. Inspection of participants' essays suggested that, in this supposedly neutral condition, many had focused on the self (e.g., what a healthy nutrition means to them personally), while some focused on others or on both. Hence, this exploratory condition did not seem an adequate neutral control condition to be included in the main analyses.

${ }^{5}$ Only data from participants who completed the whole online survey and were unfamiliar with the manipulations was analysed here; including $\mathrm{N}=19$ additional participants with incomplete data or who had participated in similar studies before (i.e., who were familiar with hypotheses and the purpose of manipulations due to debriefings from previous studies) yields similar, slightly weaker results.

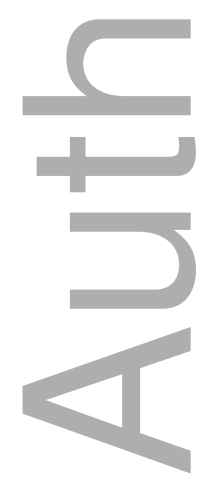


Table 1. Means (Standard Deviations) for perceived responsibility as a function of power and cognitive focus in Experiments 2 and $3(\mathrm{~N}=85$ and 89)

\begin{tabular}{c|l|l|l}
\hline \multicolumn{2}{l}{} & \multicolumn{1}{l}{ Experiment 2 } & \multicolumn{1}{c}{ Experiment 3 } \\
\hline other-focus & low power & $5.13(.97)^{\mathrm{a}}$ & $3.13(1.69)^{\mathrm{a}}$ \\
& high power & $6.57(.84)^{\mathrm{b}}$ & $5.42(2.03)^{\mathrm{b}}$ \\
\hline self-focus & low power & $5.46(1.06)^{\mathrm{a}}$ & $3.89(1.43)^{\mathrm{a}}$ \\
& high power & $5.95(1.26)^{\mathrm{a}(\mathrm{b})}$ & $4.01(1.85)^{\mathrm{a}}$ \\
\hline perspective taking & low power & - & $3.74(1.88)^{\mathrm{a}}$ \\
& high power & - & $4.18(1.55)^{\mathrm{a}(\mathrm{b})}$ \\
\hline
\end{tabular}

Note. Means with different superscripts differ from each other in simple between-cell comparisons at $\mathrm{p}<.05$; means with the same superscript in brackets differ marginally at $\mathrm{p}<$ .10 ; means with the same superscripts do not differ significantly at $\mathrm{p} \geq .10$ 


\section{Figure Captions}

Figure 1. Mean perceived responsibility (error bars represent $+/-1$ standard error) as a function of Focus and Power in Experiment $2(\mathrm{~N}=85)$. Depicted p-values refer to simple comparisons between the two power conditions, respectively.

Figure 2. Mean perceived responsibility (error bars represent $+/-1$ standard error) as a function of Focus and Power in Experiment $3(\mathrm{~N}=89)$. Depicted p-values refer to simple comparisons between the two power conditions, respectively.

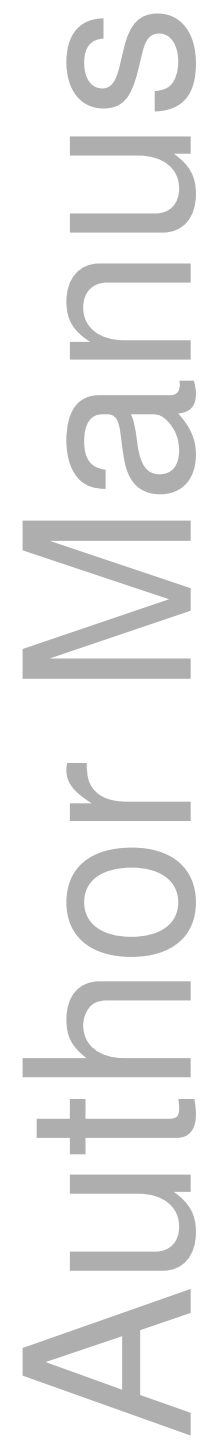




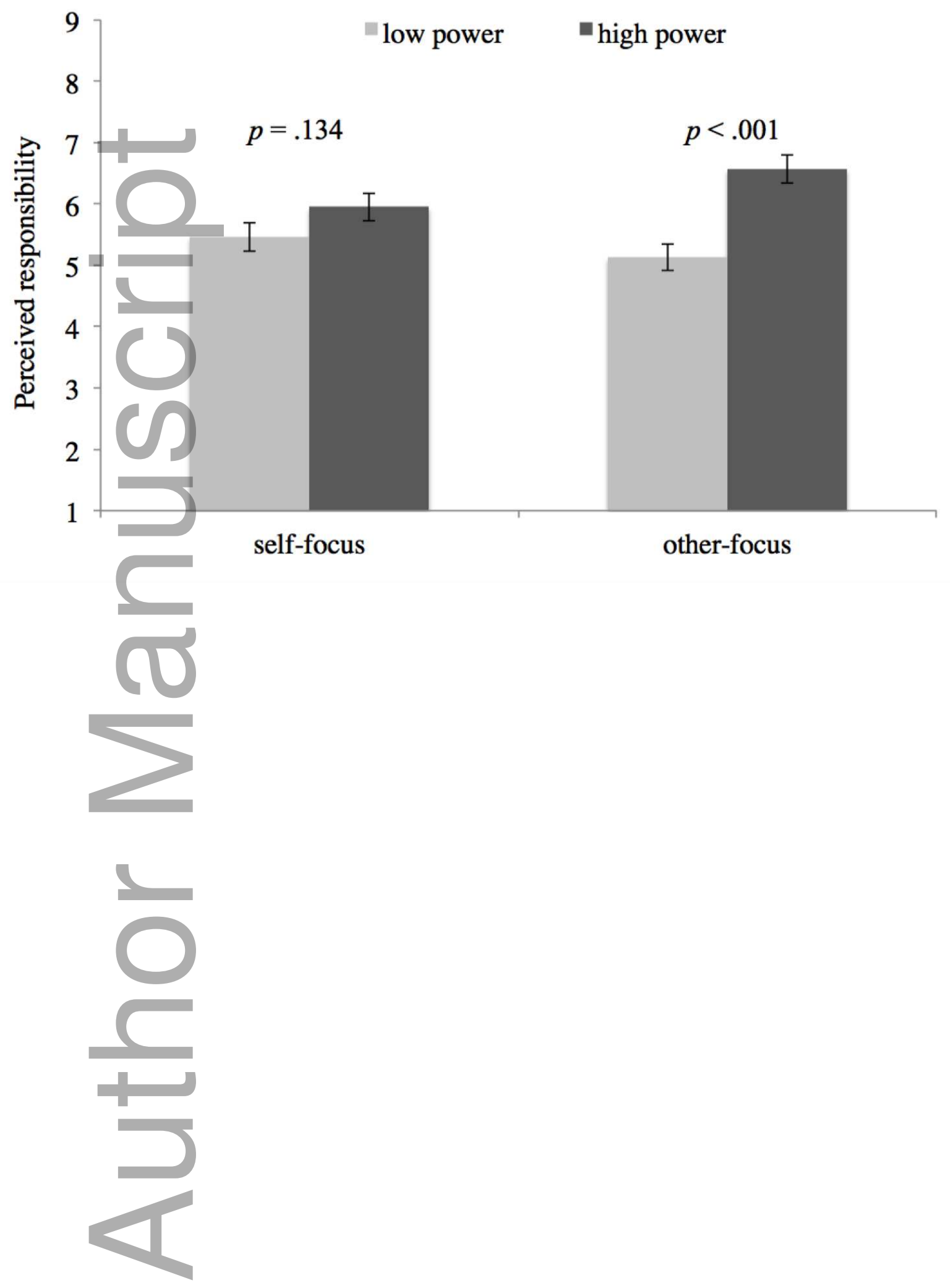




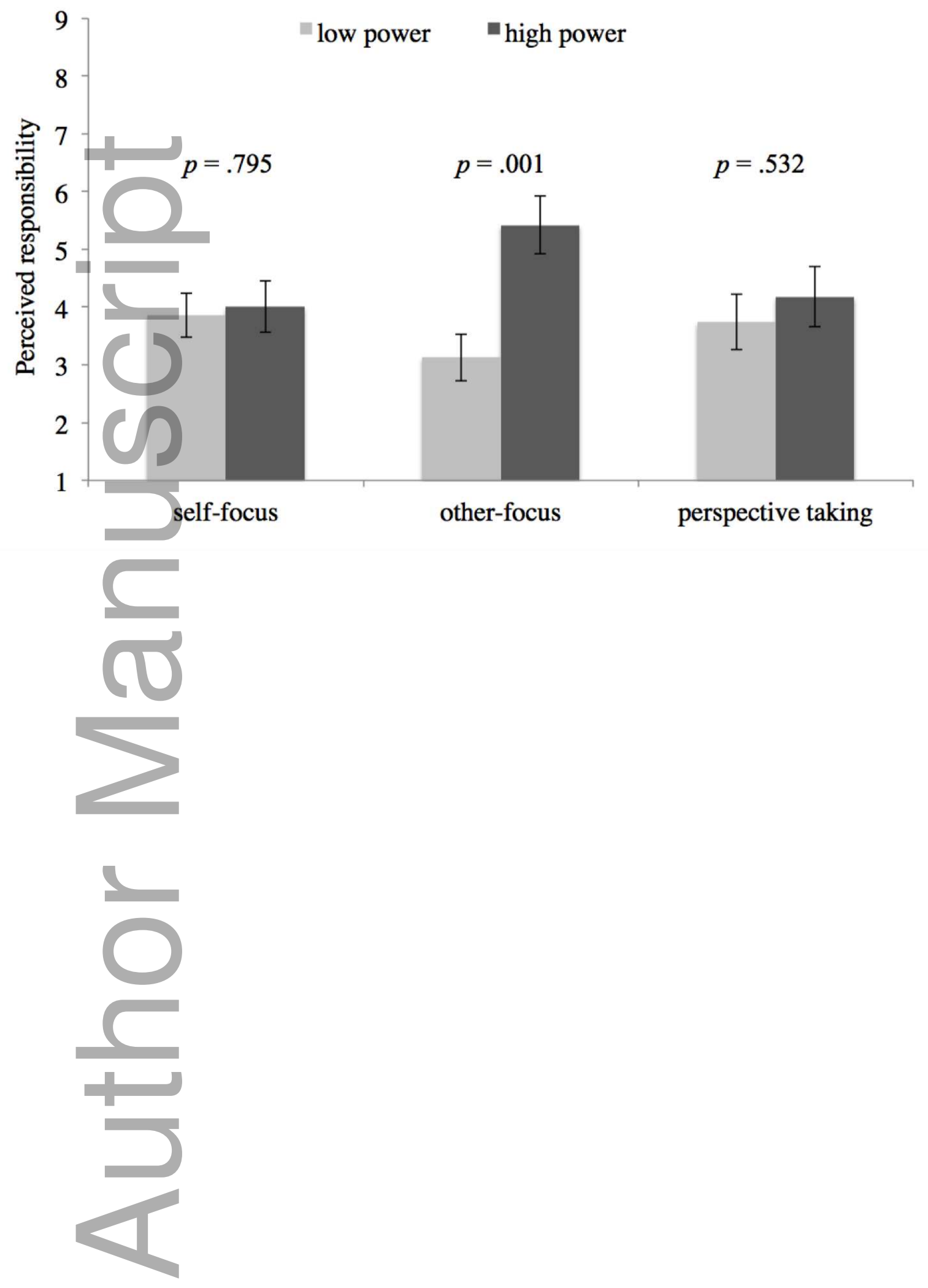




\section{University Library}

\section{- M M N E R VA A gateway to Melbourne's research publications}

Minerva Access is the Institutional Repository of The University of Melbourne

\section{Author/s:}

Scholl, A;Sassenberg, K;Scheepers, D;Ellemers, N;de Wit, F

Title:

A matter of focus: Power-holders feel more responsible after adopting a cognitive otherfocus, rather than a self-focus

\section{Date:}

2017-03-01

\section{Citation:}

Scholl, A., Sassenberg, K., Scheepers, D., Ellemers, N. \& de Wit, F. (2017). A matter of focus: Power-holders feel more responsible after adopting a cognitive other-focus, rather than a self-focus. BRITISH JOURNAL OF SOCIAL PSYCHOLOGY, 56 (1), pp.89-102. https:// doi.org/10.1111/bjso.12177.

Persistent Link:

http://hdl.handle.net/11343/292182 